\title{
ПРОБЛЕМИ СТВОРЕННЯ ЕЛЕКТРОКАРДІОГРАФІВ 3 ПІДВИЩЕНОЮ РОЗДІЛЬНОЮ ЗДАТНІСТЮ
}

\author{
Зубков С.В., інженер \\ szub284@gmail.com \\ Козій M.I., аспірант \\ mykolakoziy@ukr.net \\ Кафедра біомедичної інженерії \\ Київ, Украӥна
} Національний технічний університет Украӥни "Київський політехнічний інститут імені Ігоря Сікорського”

\begin{abstract}
Реферат - метод електрокардіографії високої роздільної здатності (ВРЗ) дає можливість відокремити і проаналізувати низькоамплітудні (5-20мкВ з частотами від 20Ги) сигнали, які недоступні для аналізу з використанням традиційних методів і містять


частотного діапазону з боку нижніх частот призводить до спотворення сегмента ST, Ti U хвиль, аз боку високих - до згладжування $Q R S$-комплексу $i$ зниження крутизни його схилів $i$ амплітуди R-хвилі. Використання потужних математичних методів для статистичної обробки зашумлених сигналів принципово поступається в точності прямій реєстрачї. Метою статтіє дослідження впливу частоти квантування, оптимального розподілу підсилення по каскадах, формування АЧХ та фільтрачії для покращення реєстрації слабких сигналів. Верхня частота смуги пропускання більшості сучасних вітчизняних електрокардіографів дорівнює 12Ги. В іншому діапазоні частот він не відповідає вимогам стандартів з точки зору похибки вимірювання напруги. Зі збільшенням кількості активних розрядів АЦП частота верхньої межі смуги катастрофічно падає. Задача формулюється наступним чином: вибрати частоту дискретизаиії, яка забезпечує перетворення вхідного сигналу в цифрову форму з потрібною похибкою дискретизації верхньої гармоніки вхідного сигналу. Складність полягає у тому, що з ростом частоти збільщується можслива похибка, тим більще, що амплітуда цих компонентів зменшується з ростом частоти в силу природнього обмеження потужності джерела сигналу. Тому впровадили в програмне забезпечення всіх електрокардіографів підсилений режим, Це дозволяс метрологічно правильно вимірювати цей параметр. Важливим є правильне проектування цифрових фільтрів, частотні характеристики яких є періодичнии. Моделювання введення аналогового фільтру перед АЦП показало суттєве зменшення амплітуди періодичних смуг пропускання цифрового фільтру.
\end{abstract}

Ключові слова: частота квантування, похибка вимірювання, смуга пропускання, придушення мережевої перешкоди, фільтрація.

\section{I. ВСТУП}

Метод електрокардіографії високої роздільної здатності (ВР3) привертає все більшу увагу медичної спільноти, і дає можливість, відокремити і проаналізувати низько амплітудні (5-20 мкВ з частотами від 20 Гц і вище) сигнали, які недоступні для аналізу 3 використанням традиційних методів ЕКГ запису i містять важливу діагностичну інформацію. Основною цього методу в даний час $\epsilon$ комп'ютерне підсилення, усереднення і фільтрація різних частин електрокардіограми 3 їх подальшою математичної обробкою 3 метою виділення корисного сигналу від завад, що в свою чергу у кілька разів перевищують його.
На підтримку цієї тенденції у Таблиці 1 наведено технічні характеристики для деяких нових моделей електрокардіографів, до яких пред'являються технічні вимоги, що відповідають вже старому, але повністю аналоговому електрокардіографу 6 NEC 4.

Вважається, що діапазон частот, що займає кардіокомплекс, охоплює діапазон від 0,05 до 800 Гц. Звуження цього частотного діапазону 3 боку нижніх частот призводить до спотворення сегмента ST, T і U хвиль, а з боку високих - до згладжування QRS-комплексу i зниження крутизни його схилів i амплітуди R-хвилі. 
Таблиця 1. Технічні характеристики сучасних електрокардіографів

\begin{tabular}{|c|c|c|c|c|}
\hline 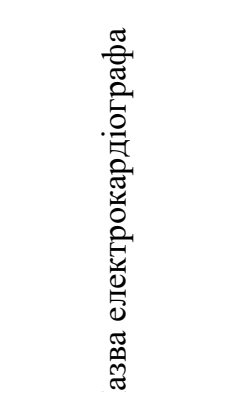 & 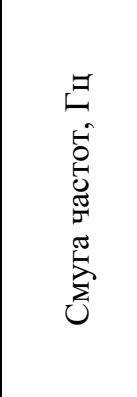 & 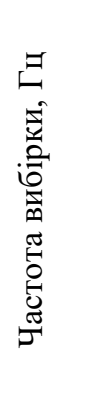 & 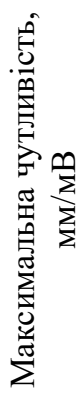 & 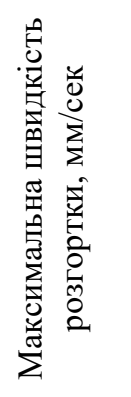 \\
\hline 6 NEC 4 & $0-200$ & & $>36$ & $100 ; 200$ \\
\hline $\begin{array}{l}\text { "Поли-Спектр- } \\
\text { 12" (ООО } \\
\text { «Нейрософт», } \\
\text { РФ) }\end{array}$ & $0-250$ & $10^{4}$ & 40 & $100 ; 200$ \\
\hline $\begin{array}{l}\text { Кардиотехника } \\
\text { - ЭКГ-8» (ЗАО } \\
\text { «Инкарт», РФ) }\end{array}$ & -250 & $10^{4}$ & 100 & 100 \\
\hline $\begin{array}{c}\text { КФС } 01.002 \\
\text { (ЗАО "Микард- } \\
\text { Лана", РФ) }\end{array}$ & $\begin{array}{c}100 \\
\text { (верхня } \\
\text { частота) }\end{array}$ & $2 \cdot 10^{4}$ & 40 & 100 \\
\hline
\end{tabular}

Основною функцією електрокардіографа $є$ реєстрація електрокардиосигналу та відображення його. Використання потужних математичних методів для статистичної обробки зашумлених сигналів все ще принципово поступається в точності прямій реєстрації електрокардиосигналів.

\section{ІІ. ПОСТАНОВКА ЗАДАЧІ}

Задачею роботи було дослідження впливу частоти квантування і оптимального розподілу підсилення по каскадах на характеристику роздільної здатності та формування АЧХ для покращення реєстрації слабких сигналів.

\section{III. ЧАСТОТА КВАНУВАННЯ ЯК ОСНОВНИЙ ПАРАМЕТР ПІДВИЩЕННЯ РОЗДІЛЬНОЇ ЗДАТНОСТІ}

Амплітудно-частотна характеристика (АЧХ) $є$ метрологічною стандартизованою характеристикою електрокардіографа в сталому стані (після перехідного процесу) при подачі синусоїдального сигналу на вхід. Саме тому він не може повноцінно служити критерієм ідентичності (в сенсі адекватного відображення вхідного сигналу) електрокардіографів. Для порівняння, як приклад, наведено записи тестового прямокутного сигналу $з$ амплітудою $1 \mathrm{MB}$ i частотою 0,5 ц (рис.1), виконані за допомогою електрокардіографа новітньої версії «ЮКАРД-200» (верхні електрокардіограми) і попередньої версії «ЮКАРД-100» (нижні електрокардіограми), які мають однакову частотну характеристику i постійну часу, задовольняючи [1], і ті ж схемні рішення. Але в першому випадку вжито заходи, які дозволяють реєструвати цей сигнал так, ніби смуга електрокардіографа поширилася до 0 Гц.

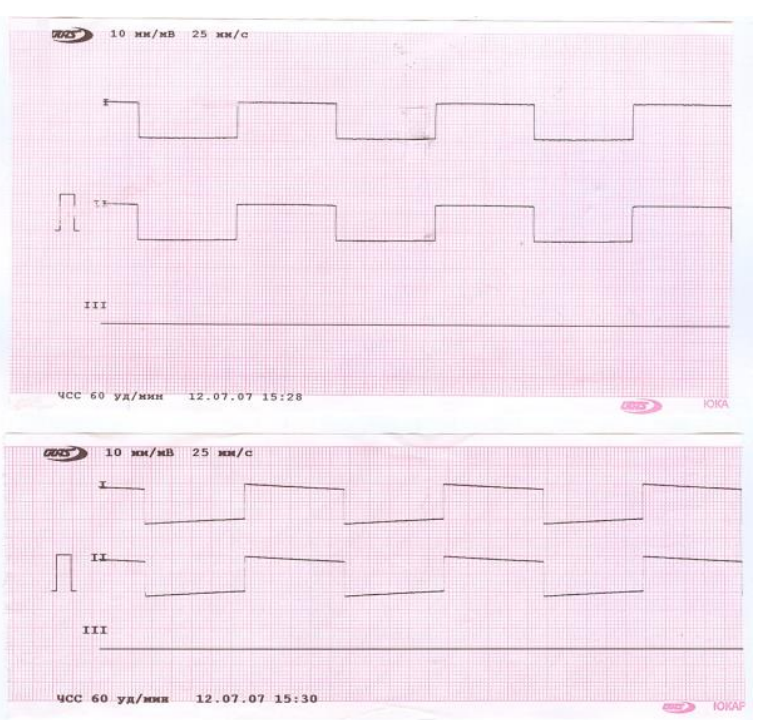

Рис.1. Тестові сигнали ЕКГ, які зареєстровані електрокардіографами «ЮКАРД-200» та «ЮКАРД-100».

Наведені тестові електрокардіограми $\epsilon$ хорошим прикладом альтернативного підходу [2] - коли нормалізуються помилки при відображенні амплітудних та часових величин фрагментів для деякого зразкового електрокардіосигналу. Тобто нормування здійснюється в часовій області, а не в частотній. В [1] передбачено аналогічні випробування.

Крім того, на нашу думку, важливим аспектом є наступне. У тому випадку, якщо вхідний сигнал постійний, період вибірки $\mathrm{T}_{\mathrm{c}}$ не має суттєвого значення і точність перетворення аналогового сигналу в цифровий сигнал визначається кількістю розрядів АЦП.

Однак, якщо вхідний сигнал змінюється (рис. 2), тоді, як показано, наприклад, в [3], визначальним фактором точності $\epsilon$ частота дискретизації:

$$
f_{c}=\frac{1}{T_{c}}
$$




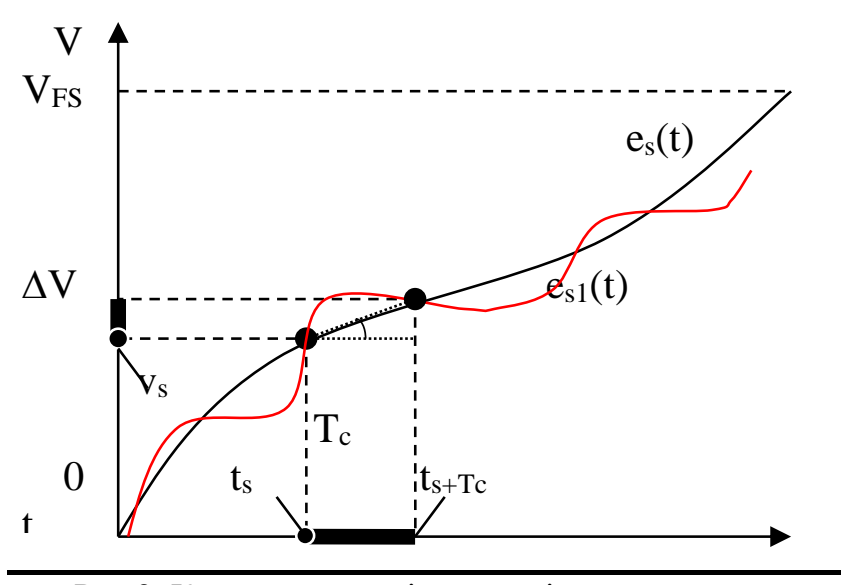

Рис.2. Квантування змінного вхідного сигналу.

3 рис. 2 видно, що для сигналу $\mathrm{e}_{\mathrm{s} 1}(\mathrm{t})$ період квантування $\mathrm{T}_{\mathrm{c}}$ вибраний дуже великим, тому інформацію про його характерну поведінку буде втрачено.

Нехай максимальне вхідне значення, яке відповідає n розрядам АЦП, дорівнює $\mathrm{V}_{\mathrm{FS}}$. Для забезпечення необхідної точності відтворення $\left(2^{-n}\right)$ вхідного сигналу е $e_{s}(t)$, необхідно, щоб за час вибірки його зміна не перевищувала:

$$
\Delta V \leq 2^{-n} V_{F S}
$$

Враховуючи, з іншого боку

$$
\left.\Delta V \cong \frac{d e_{S}(t)}{d t}\right|_{t=t_{S}} T_{C}
$$

Отримаємо:

$$
\left.\frac{d e_{S}(t)}{d t}\right|_{t=t_{S}} \leq 2^{-n} \frac{V_{F S}}{T_{C}} .
$$

Смугу вхідного сигналу можна охарактеризувати найвищою гармонічною складовою:

$$
e_{S}(t)=\frac{V_{F S}}{2} \operatorname{Sin}\left(2 \pi f_{B} t\right)
$$

Підставимо (5) в (4), і враховуючи, що максимальне значення похідної синуса набуває в нулі, отримаємо:

$$
\left.2 \pi f_{B} \frac{V_{F S}}{2} \operatorname{Cos}\left(2 \pi f_{B} t\right)\right|_{t=0} \leq 2^{-n} \frac{V_{F S}}{T_{C}} .
$$

Звідки верхня межа смуги вхідного сигналу, який перетворюється 3 точністю не менше $2^{- \text {n }}$, буде дорівнювати:

$$
f_{B}=\frac{1}{2^{n} \pi T_{C}}=\frac{f_{C}}{2^{n} \pi} .
$$

Отже, наприклад, при частоті вибірки $\mathrm{f}_{\mathrm{c}}=400$ Гц i кількості активних розрядів $\mathrm{n}=7$ (для забезпечення допустимої похибки вимірювання напруги відповідно до [1] з деяким виробничим запасом) верхня частота смуги пропускання електрокардіографа дорівнює 1 Гц.

В іншому діапазоні частот верхня частота смуги пропускання електрокардіографа не відповідає вимогам [1] з точки зору точності. Далі очевидно, що зі збільшенням кількості $\mathrm{n}$ активних розрядів АЦП, тенденція до чого чітко простежується, частота верхньої межі $f \circ$ катастрофічно падає.

Можна зробити висновок про те, що збільшення кількості розрядів АЦП (на нашу думку вище $\mathrm{n}=8$ ) якісно не покращує діагностичні можливості електрокардіографа. До такої ж думки прийшлі наприклад, автори Хаустов А. В. і Антонова I. С. та ін. [4].

Передбачаючи можливі заперечення та посилаючись на відому теорему Котельникова, необхідно відзначити наступні обставини. Поперше, у теоремі Котельникова річ йде про критерій вибору частоти квантування, а математичне відображення цього факту не являє собою алгоритм відновлення початкового безперервного сигналу по дискретним вибіркам. По-друге, електрокардіографи в більшості випадків не вирішують цю проблему - проблему отримання вихідного аналогового сигналу 3 оцифрованого вхідного аналогового сигналу. Іншими словами, задачу можна сформулювати наступним чином: вибрати частоту дискретизації, яка забезпечує перетворення вхідного сигналу в цифрову форму з потрібною точністю дискретизації, якщо про вхідний сигнал відомо тільки те, що він не періодичний, обмежений по амплітуді i має скінченне значення швидкості зростання, яка відома або задана. 
Якщо подивитись на параметри полоси, частоти вибірки і розрядності АЦП, які заявлені фірмами в проспектах на електрокардіографи, можна за допомогою формули (7) оцінити їх адекватність.

Отже, справедливе наступне питання: як в таких умовах працює алгоритм попереднього синдромального заключення? Це питання $\epsilon$ важливим, оскільки аналогово-цифрові електрокардіографи не можуть адекватно відобразити частоти вище декількох герц. Очевидно, що доступний для аналізу (з точки зору точності) спектр більшості інформаційних ознак ЕКГ лежить нижче цих частот. Також складність полягає у тому що з ростом частоти збільшується можлива похибка, тим більше, що амплітуда цих компонентів зменшується 3 ростом частоти в силу природнього обмеження потужності джерела сигналу.

Наступну серйозну проблему представляють завади. Найбільший вклад в сумарну похибку вимірювання інформативних параметрів ЕКГ, як показано в [5] і в наступних виданнях, вносять: синфазні завади від мережі живлення i різницеві низькочастотні, які зміщують ізоелектричну лінію.

Ручне вимірювання параметрів ЕКГ по запису на паперовій смужці за допомогою збільшувавного скла і штангенциркуля, вже застаріло. Також необхідно відмітити, що коректне вимірювання рівня власних шумів електрокардіографа, представляє складність, оскільки товщина лінії однакова 3 максимально допустимою шириною шумової доріжки: 0,4 мм (20мкВ) при чутливості 20 мм/мВ.

Тому в програмне забезпечення всіх електрокардіографів «ЮКАРД» впровадили тестовий підсилений режим, який використовується під час приймальних випробувань, що забезпечує чутливість до 200 мм /MB і швидкість розгортки $100 \mathrm{~mm} / \mathrm{c}$. Це дозволяє метрологічно правильно вимірювати цей параметр. У серійних приладах типове значення шуму становить 10-15мкB (RMS 3,5$5,2 \mathrm{M \kappa}$ В).

Для ілюстрації вищесказаного представлясмо фрагмент ЕКГ в I відведенні реального пацієнта, взятий в тестовому посиленому режимі $(50 \mathrm{~mm} / \mathrm{MB}, 100 \mathrm{mм} / \mathrm{c}$, смуга

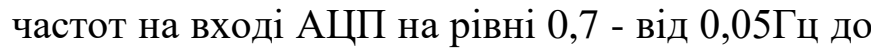
150Гц, ширина паперу 110 мм) без використання будь-яких фільтрів (рис. 3).

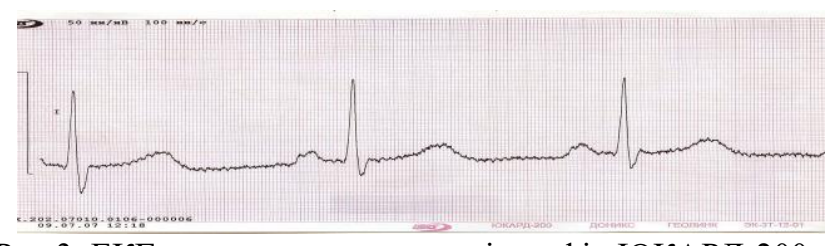

Рис.3. ЕКГ, знята на електрокардіографі «ЮКАРД-200» 3 реального пацієнта у посиленому режимі баз фільтрів.

Якщо врахувати все вище сказане то загальний підхід до проектування вхідних підсилювачів ЕКГ, який дозволяє мінімізувати рівень їх власних шумів, викладено в [5].

При послідовному підключені підсилювальних каскадів коефіцієнти придушення синфазних завад $\left(K_{П С П}\right)$ не перемножуються, а має місце функціональний зв'язок між коефіцієнтом придушення синфазних завад багаткаскадних пристроїв i коефіцієнтами режекції $\left(H_{i}\right)$ та дискримінації $\left(F_{i}\right)$ для кожної із послідовно з'єднаних схем.

Наприклад, у випадку послідовного з'єднання трьох підсилювачів $A, B \quad i \quad C$ iï результуючий коефіцієнт придушення синфазних завад наступним чином залежить від коефіцієнтів $H_{i} i F_{i}$ окремих схем.

$$
K_{\text {ПСП }}=\frac{1}{\frac{1}{H_{A}}+\frac{1}{F_{A} H_{B}}+\frac{1}{F_{A} F_{B} H_{C}}+\frac{1}{F_{A} F_{B} F_{C}}}
$$

де визначено наступні коефіцієнти:

$H=\frac{K_{P P}}{K_{C P}}$

коефіцієнт режекції, який характеризує симетрію схеми до синфазного сигналу відносно підсилення корисного різницевого сигналу;

$F=\frac{K_{P P}}{K_{C C}}$ - коефіцієнт дискримінації, що показує, у скільки разів більше схема посилює різницевий сигнал, ніж синфазний;

$K_{P P}=\frac{V_{P}^{B b I X}}{V_{P}^{B X}}$

сигналу (при $V_{C}^{B X}=0$ );

$K_{C C}=\frac{V_{C}^{B b X}}{V_{C}^{B X}}$

- коефіцієнт передачі синфазного сигналу (при $V_{P}^{B X}=0$ ); 
$K_{C C}=\frac{V_{P}^{B b I X}}{V_{C}^{B X}}$

- коефіцієнт передачі синфазного

сигналу в різницевий (при $V_{P}^{B X}=0$ );

$V_{C}^{B X}=\frac{V_{A}+V_{B}}{2}$

- синфазна вхідна напруга;

$V_{P}^{B X}=\frac{V_{A}-V_{B}}{2}$

- різницева вхідна напруга;

$A, B$ - входи схем.

Отже можна зробити висновок: на придушення синфазної завади найбільше впливають коефіцієнти режекції і дискримінації 1-го каскаду і коефіцієнт режекції 2-го каскаду. Вплив параметрів вхідного ланцюга на $K_{П с п}$ можна з'ясувати, якщо розглянути його еквівалентну схему (рис. 4) [2].



Рис.4. Еквівалентна схема вхідного ланцюга.

На рисунку 4 позначені:

$R_{A}, R_{B}$ - еквівалентні опори джерела ЕКС плюс опір “шкіра-електрод” та електрода;

$R_{A B}, R_{A O}, R_{B O}$ - повні вхідні опори вхідного каскаду.

В роботі [5] вказується, що для досягнення коефіцієнта придушення синфазної завади, яке дорівнює $10^{4}$, опір між входом та нейтральним провідником має бути $R_{A, B} \geq 35$ МОм, А диференціальний опір $R_{A B} \geq 300$ кОм. Це автоматично означає, що ємність сигнальних провідників кабеля відведень відносно нейтрального має не перевищувати 50 пф на 1м довжини.

Для зменшення впливу цієї ємності екранованих провідників на придушення синфазних завад на екран необхідно подати напругу синфазної завади.

Окремою проблемою $є$ проектування фільтрів, які придушують завади мережі.

Прикладом вдалого вирішення може бути 50 Гц-фільтр електрокардіографа “SCHILLER” AT6. У ньому постійну заваду пригнічують, а короткі (200-300 мс) фрагменти ЕКГ, які лежать у цій частотній області, проходять без змін. Для реєстрації ЕКГ підвищеної чутливості актуальною $\epsilon$ задача придушення гармонік мережі - 100,150 , 200 і 250 Гц, амплітуда яких в реальних умовах може перевищувати відповідні компоненти ЕКГ.

Дуже важливим є грамотне проектування цифрових фільтрів, частотні характеристики яких $€$ періодичними. Наприклад, введення аналогового фільтру другого порядку 3 передаточною функцією

$$
\begin{aligned}
& W(s)=\frac{1}{T^{2} s^{2}+2 \xi T s+1}, \\
& \text { де } T=0.005 \mathrm{sec}, \xi=0.5
\end{aligned}
$$

перед АЦП дозволило суттєво зменшити періодичні смуги пропускання цифрового фільтру (Рис.5), де $f_{0}=500 \Gamma u-$ частота квантування:
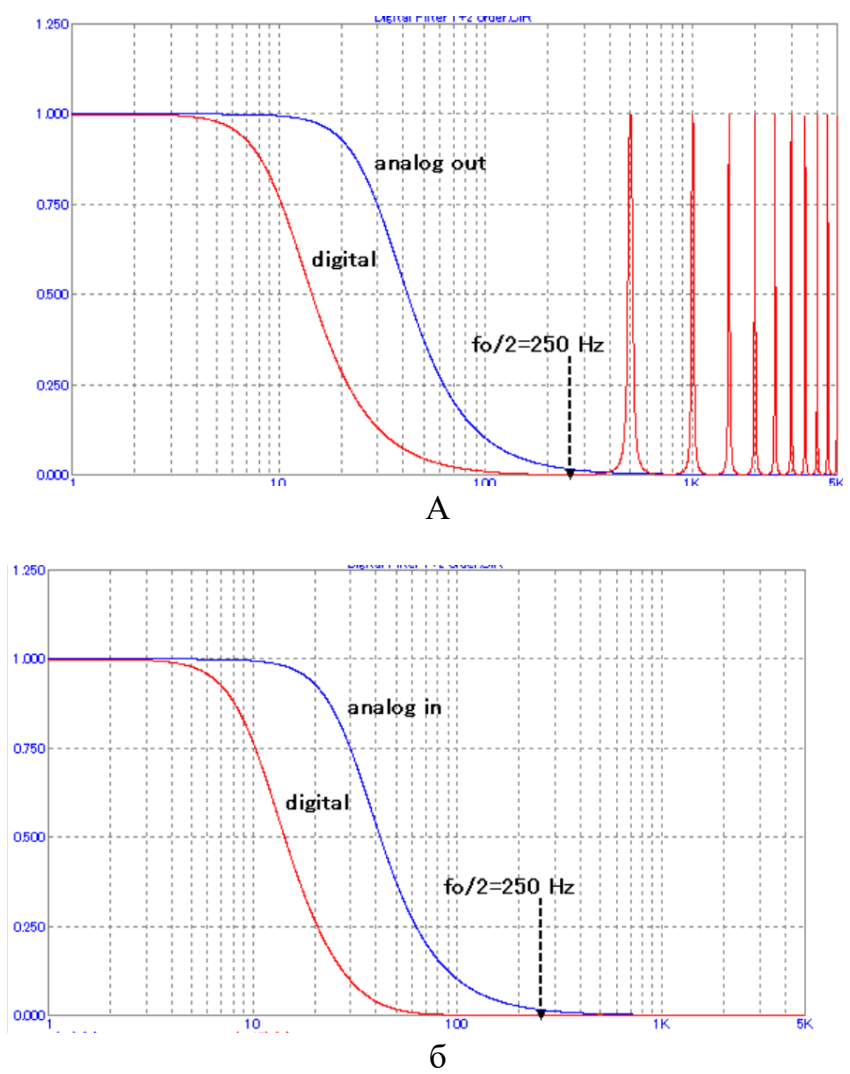

Рис.5. Амплітудно-частотні характеристики цифрового фільтру другого порядку (червоні криві) до (а) та після

(б) введення в схему аналогового фільтру.

Такі гребінчасті фільтри застосовується в багатьох сучасних sigma-delta АЦП. 


\section{IV. ВИСНОВКИ}

Виконані дослідження впливу частоти квантування i оптимального розподілу підсилення по каскадах на характеристику роздільної здатності та формування АЧХ електрокардіографів для покращення реєстрації слабких сигналів дають змогу зробити наступні висновки:

1. На підвищення точності i роздільної здатності аналого-цифрових електрокардіографів більш суттєво впливає підвищення частоти вибірки, а не розрядність АЦП.

2. Рівень наведених до входу своїх шумів вхідних підсилювачів порядку 2мкВ (середньоквадратичних, не зважених) можна вважати сьогодні практичною (економічно розумною) верхньою межею.

3. Ключовим моментом у ЕКГ ВРЗ є придушення мережевої перешкоди та іiі гармонік. Для цього вхідний каскад повинен мати великий коефіцієнт придушення синфазної перешкоди цих частотах, а режекторні фільтри повинні бути налаштовані на основну частоту мережі і її гармоніки і мати гладку перехідну характеристику.

4. Проектування цифрових фільтрів повинно проводитись 3 урахуванням необхідності придушення періодичних смуг пропускання.

\section{ПЕРЕЛІК ПОСИЛАНЬ}

1. International Standart IEC 60601-2-51. Medical electrical equipment-Part 2-51: Particular requirements for safety, including essential performance, of recording and analyzing single channel and multichannel electrocardiographs. [Електронний ресурс]. - 2011. - Режим доступу до pecypcy: https://standards.globalspec.com/std/1401966/iec60601-2-25.

2. Р 50.2.009-2011 Государственная система обеспечения единства измерений. Электрокардиографы, электрокардиоскопы и электрокардиоанализаторы. Методика поверки [Електронний ресурс]. - 2011. - Режим доступу до ресурсу: https://docs.cntd.ru/document/1200097950.

3. Benjamin C. Kuo B. C. Digital Control Systems / Benjamin C. Benjamin C. Kuo. - Oxford: Oxford University Press, 1995. - 784 c. - (2nd edition).

4. Хаустов А. В. Влияние характеристик регистраторов и применяемых отведений экг на выявление поздних потенциалов желудочков при холтеровском мониторировании / А. В. Хаустов, В. С. Морошкин, И. С. Антонова. // Вестник аритмологии. - 2007. - №47. - С. 23 28.

5. Янушкевичюс 3. И. Дополнительно усиленная электрокардиограмма. / 3. И. Янушкевичюс, Л. В. Чирейкин, А. А. Праневичюс. - Ленинград: Медицина, 1982. $-184 \mathrm{c}$. 


\section{ПРОБЛЕМЫ СОЗДАНИЯ ЭЛЕКТРОКАРДИОГРАФОВ ВЫСОКОГО РАЗРЕШЕНИЯ}

Зубков С.В., инженер szub284@gmail.com Козій М.I., аспирант mykolakoziy@ukr.net Кафедра биомедицинской инженерии Национального технического университета Украины “Киевский политехнический институт имени Игоря Сикорского”, м. Киев, Украина

Реферат - Метод электрокардиографии высокой разрешающей способности (ВРС дает возможность разделять и анализировать низкоамплитудные (5-20 мВ с частотами от 20 Ги) сигналы, недоступные для анализа традиционными методами и содержащие важную диагностическую информацию. Полоса частот, занимающая кардиокомплексом, охватывает диапазон от 0,05 до 800 Ги. Сужение этого частотного диапазона с более низких частот приводит к искажению сегмента волн $S T, T$ и $U$, а с высокой стороны к сглаживанию $Q R S$-комплекса и снижению крутизны его склонов и амплитуды $R$-волны. Использование мощных математических методов статистической обработки шумящих сигналов принщиипально уступает по точности прямой регистрации. Целью статьи является исследование влияния частоты квантования, оптимального распределения усиления по каскадам, формирования АЧХ и фильтрации на улучшение регистрачии слабых сигналов. Верхняя полоса частот большинства современных отечественных электрокардиографов составляет 1-2Ги. В другом диапазоне частот он не соответствует требованиям стандартов с точки зрения погрешности измерения напряжения. При увеличении числа активных разрядов АЦП частота верхней границы полосы катастрофически падает. Задача формулируется следующим образом: выбрать частоту дискретизачии, которая обеспечивает преобразование входного сигнала в ичифровую форму с необходимой погрешностью дискретизации верхней гармоники входного сигнала. Сложность заключается в том, что по мере увеличения частоты увеличивается возможная погрешность, тем более что амплитуда этих компонентов уменьшается с увеличением частоты из-за естественного ограничения мощности источника сигнала. Поэтому в программное обеспечение был введен усиленный режим работы всех электрокардиографов, что позволяет метрологически корректно измерять данный параметр. Важно правильно спроектировать ичифровые фильтры, частотные характеристики которых являются периодическими. Моделирование введения аналогового фильтра перед АЦП показало значительное снижение амплитуды периодических полос пропускания иифрового фильтра.

Ключевые слова: частота квантования, погрешность измерения, полоса пропускания, подавление сетевых препятствий, фильтрация. 


\title{
UDC 616.12-073.97 PROBLEMS OF CREATING HIGH- RESOLUTION ELECTROCARDIOGRAPHS
}

\author{
Zubkov.S.V., engineer \\ szub284@gmail.com \\ Kozii M.I., PhD student \\ mykolakoziy@ukr.net \\ Department of Biomedical Engineering \\ National Technical University of Ukraine \\ "Igor Sikorsky Kyiv Polytechnic Institute", \\ Kyiv, Ukraine
}

\begin{abstract}
The method of high-resolution electrocardiography (HRE) is possible to separate and analyse low-amplitude (5-20 $\mathrm{mV}$ with frequencies from $20 \mathrm{~Hz}$ ) signals that are inaccessible for analysis by traditional methods and contain important diagnostic information. The frequency band occupying the cardiocomplex covers the range from 0.05 to $800 \mathrm{~Hz}$. Narrowing this frequency range from lower frequencies leads to distortion of the ST, T and U wave segment, and on the high side to smoothing the QRS complex and reducing the steepness of its slopes and the amplitude of the $R$-wave. The use of powerful mathematical methods of statistical processing of noisy signals is fundamentally inferior in accuracy to direct registration. The article is aimed at studying the influence of quantization frequency, optimal distribution of amplification by cascades, formation of FR and filtering on improving the registration of weak signals. The upper frequency band of most modern domestic electrocardiographs is $1-2 \mathrm{~Hz}$. In another frequency range, it does not meet the requirements of the standards in terms of voltage measurement error. As the number of active ADC discharges increases, the frequency of the upper band boundary drops catastrophically. The task is formulated as follows: to select the sampling rate, which ensures the conversion of the input signal into digital form with the necessary error of digitization of the upper harmonic of the input signal. The main difficulty is that as frequency increases the possible of errors increases as well. Since the amplitude of these components decreases with higher frequency due to the natural limitation of the power of the signal source. Therefore, an enhanced mode of operation of all electrocardiographs was introduced into the software, which allows this parameter to be measured metrologically correctly. It is important to properly design digital filters whose frequency characteristics are periodic. Simulations of the introduction of an analog filter in front of the ADC showed a significant decrease in the amplitude of the periodic bandwidths of the digital filter.
\end{abstract}

Keywords: quantization frequency, measurement error, bandwidth, suppression of network obstacles, filtering. 